\title{
Sebuah Kajian Etik: Bolehkah Dokter Spesialis Obstetri dan Ginekologi Melakukan Tindakan Sesar Berdasarkan Permintaan Pasien Tanpa Indikasi Obstektrik yang Nyata? \\ Wawang Sukarya ${ }^{\mathrm{I}, 2}$, Mohammad Baharuddinn ${ }^{\mathrm{I}, 3}$, Yunizaf ${ }^{\mathrm{1}, 4}$ \\ ${ }^{1}$ Majelis Kehormatan Etik Kedokteran Pengurus Besar Ikatan Dokter Indonesia \\ ${ }^{2}$ Departemen Obstetri dan Ginekologi, Fakultas Kedokteran Universitas Islam Bandung, Bandung \\ ${ }^{3}$ Departemen Obstetri dan Ginekologi, Rumah Sakit Bersalin Budi Kemuliaan, Jakarta \\ ${ }_{4}^{4}$ Departemen Obstetri dan Ginekologi, Fakultas Kedokteran Universitas Indonesia/Rumah Sakit Cipto Mangunkusumo, Jakarta
}

\author{
Kata Kunci \\ etik; persalinan sesar; permohonan pasien \\ Korespondensi \\ wssukarya@yahoo.com \\ contact@ilmiah.id \\ Publikasi \\ (C) 2017 JEKI/ilmiah.id \\ DOI \\ I0.26880/jeki.viit.3 \\ Tanggal masuk: I2 Juli 2017 \\ Tanggal ditelaah: 25 Juli 2017 \\ Tanggal diterima: 18 Agustus 2017 \\ Tanggal publikasi: II Oktober 2017
}

\begin{abstract}
Abstrak Kebanggaan memiliki anak bertanggal ulang tahun unik dan berbagai alasan lainnya mendorong ibu untuk membuat permintaan prosedur persalinan sesar pada tanggal tertentu, meskipun cara persalinan pervaginam masih mampu laksana tanpa penyulit yang signifikan. Hal ini menggiring diskusi untuk menjawab dilema etik dokter dalam menanggapi permohonan pasien yang tidak disertai indikasi medis tersebut. Penelusuran literatur dilakukan untuk menganalisis risiko dan manfaat sebagai acuan penilaian etik atas prosedur persalinan sesar terencana. Menurut UU Praktik Kedokteran, pasien berhak atas pilihan pengobatan, mendapatkan penjelasan atas tindakan medik, dan menolak tindakan medis pada dirinya. Dalam kode etik Perkumpulan Obstetri Dan Ginekologi Indonesia (POGI) revisi 20I2, tindakan bedah sesar atas permintaan pasien tidak melanggar etik selama telah dilakukan informed consent khusus dan usia kehamilan sudah 39 minggu saat operasi sesar dilakukan.
\end{abstract}

\begin{abstract}
The pride of having a child with unique birthday and various other reasons encourage a mother to request cesarean delivery procedure on a certain date, even though vaginal delivery is still feasible without significant complication. This leads to a discussion of doctors' ethical dilemma in responding to patient requests which are not based on medical indications. A literature search was conducted to analyze the risks and benefits as reference for ethical assessment of planned cesarean delivery procedure. According to the Medical Practice Act, a patient has the rights to choose treatments, to obtain explanation of medical actions, and to reject medical treatment. In the code of Indonesian Society for Obstetrics and Gynecology 20I2 revision, cesarean section on maternal demand does not violate ethics as long as a special informed consent is performed and the gestational age has reached 39 weeks when the cesarean section takes place.
\end{abstract}

\section{PENDAHULUAN}

Seksio sesarea atau persalinan sesar adalah salah satu cara melahirkan bayi melalui sayatan yang dibuat di dinding abdomen dan rahim ibu. Secara alami, bayi seharusnya lahir melalui vagina (cara pervaginam), yang lebih banyak dilakukan, mudah, dan aman. ${ }^{1}$ Akan tetapi, persalinan pervaginam tidak selalu memungkinkan karena adanya faktorfaktor penyulit pada ibu dan bayi, seperti kehamilan ganda, bayi terlalu besar, kelahiran sebelum waktunya, tidak berada dalam posisi yang baik di rahim, tali pusar yang melilit pada tubuh bayi, atau didapatkan denyut jantung abnormal pada pemantauan. Selain itu, bila keadaan medis ibu tidak mendukung seperti menderita preeklampsia, diabetes mellitus, atau penyakit penyulit lainnya, kelahiran pervaginam tidak dapat dilakukan. Dalam hal ini, kelahiran sesar menjadi pilihan yang lebih aman dan terbaik untuk melanjutkan persalinan. ${ }^{2}$

Wanita yang sebelumnya pernah melahirkan sesar dapat melakukan persalinan pervaginam. Keputusan tersebut kemudian bergantung pada jarak persalinan kini dengan persalinan sesar sebelumnya (harus sudah lebih dari 3 tahun), jumlah persalinan sesar yang pernah dijalani, adanya faktor risiko yang menjadi kontraindikasi melahirkan pervaginam, kelengkapan medis rumah sakit pelaksana, dan berbagai faktor lainnya. ${ }^{3}$

\section{Tahapan Persalinan Sesar}

Sebelum persalinan sesar dilakukan, persiapan dilakukan dengan puasa 6-8 jam sebelum tindakan dan telah dilakukan informed consent yang ditandatangani oleh pasien atau keluarga. Kemudian dilakukan pengosongan rektum dengan klisma dan 
pemasangan infus dengan cairan $\mathrm{NaCl}$ fisiologis sebagai jalur cairan dan obat-obatan selama dan setelah operasi dilaksanakan. Kateter urin dipasang untuk mengosongkan kandung kemih (agar selama operasi tidak terjadi cedera kandung kemih) dan memonitor jumlah urin yang diproduksi selama operasi. Anastesi umum, blok epidural, atau blok spinal diberikan oleh dokter anestesi untuk menghilangkan rasa sakit dan gerakan tubuh pasien. Operasi sesar dilakukan dengan menyayat dinding perut sepanjang $8-9 \mathrm{~cm}$ secara vertikal atau horizontal. Setelah rongga abdomen terbuka, dicari segmen bawah uterus dan dilakukan sayatan horizontal sepanjang 8-9 cm. Bayi dilahirkan dengan meluksir kepala dengan tangan operator, kemudian tali pusat dipotong dan bayi selanjutnya ditolong oleh tenaga perawat ahli atau dokter spesialis anak. Kemudian setelah plasenta dilahirkan, dilakukan penilaian perdarahan per abdomen. Bila tidak ada perdarahan, dinding perut ditutup kembali. ${ }^{1,3}$

Pada tindakan pembedahan sesar dapat terjadi komplikasi kecil yang biasanya mudah diatasi, seperti infeksi, perdarahan, pembentukan bekuan darah di kaki, organ panggul, atau paru-paru, cedera pada usus dan/atau kandung kemih, serta reaksi terhadap obat atau anestesi yang digunakan. Pada masa pascaoperatif, pasien mungkin merasakan kram ringan (terutama jika sedang menyusui) atau nyeri pada luka sayatan. Dapat pula terjadi perdarahan pervaginam selama sekitar 1 minggu, namun dalam kasus jarang dapat terjadi hingga 4-6 minggu. ${ }^{4}$

\section{METODE}

Kami menelaah hukum, kode etik, dan berbagai peraturan di Indonesia mengenai persalinan sesar melalui situs Ikatan Dokter Indonesia, Perkumpulan Obstetri dan Ginekologi Indonesia, serta simpulan konferensi The American College of Obstetricians and Gynecologists (ACOG) pada situs ACOG. Kami juga melakukan penelusuran literatur dari basis data jurnal Up To Date, PubMed, Clinical Key, Canadian Medical Association Journal, dan Elsevier Sciences dengan kata kunci "sesar", "maternal request", dan "ethics".

\section{HASIL DAN PEMBAHASAN}

\section{Peningkatan angka persalinan sesar}

Tercatat sebesar $30.3 \%$ dari seluruh persalinan hidup di Amerika Serikat merupakan persalinan sesar primer maupun ulangan. ${ }^{5}$ Peningkatan jumlah persalinan sesar tidak terlepas dari "rantai" sesar ulangan dengan persentase hampir $91 \%$ pada tahun 2006 di Amerika. Sementara, tingkat persalinan sesar primer pun terus meningkat dengan cepat bagi wanita di semua golongan umur, ras, kondisi medis, dan kelahiran pada semua usia kehamilan. ${ }^{6}$ Seiring dengan meningkatnya jumlah persalinan sesar, angka permintaan sesar oleh ibu pun turut meningkat. ${ }^{7}$

Ibu yang dinilai mampu menjalani persalinan pervaginam dengan baik tidak jarang memilih persalinan sesar dengan alasan untuk memilih tanggal kelahiran yang cantik bagi anaknya. Mengingat konsep autonomi pasien, keinginan pasien untuk mendapatkan persalinan sesar tidak boleh dihalangi. Keputusan ini haruslah dipertimbangkan dengan hati-hati dan didiskusikan dengan dokter. ${ }^{8}$ Seperti operasi pada umumnya, ada risiko dan komplikasi yang perlu dipertimbangkan sebelum persalinan sesar dilakukan. Penimbangan risiko dan manfaat harus dilakukan secara matang. ${ }^{9}$

\section{Risiko dan manfaat sesar terencana}

Secara umum, lama rawat inap di rumah sakit tentunya akan lebih lama pada persalinan sesar dibandingkan dengan persalinan pervaginam spontan. Sementara itu, persalinan pervaginam dan sesar terencana dinilai memiliki risiko yang sama dengan sedikit perbedaan pada tingkat morbiditas ibu dan fungsi seksual postpartum. ${ }^{10}$ Meskipun demikian, sebuah studi lainnya menyatakan bahwa wanita yang melahirkan dengan operasi sesar terencana secara signifikan memiliki risiko yang lebih tinggi terhadap komplikasi seperti henti jantung postpartum, hematoma, histerektomi, infeksi masa nifas, komplikasi anestesi, tromboemboli vena, dan perdarahan (yang kadang membutuhkan histerektomi) dibandingkan dengan mereka yang menjalani persalinan pervaginam. ${ }^{11}$ Mengingat bahwa risiko plasenta previa atau akreta meningkat pada persalinan sesar berulang, persalinan sesar terencana merupakan menjadi pilihan yang kurang baik bagi wanita yang ingin memiliki lebih banyak anak..$^{12}$ 
Salah satu alasan lainnya dari permintaan sesar oleh ibu adalah keinginan untuk mendapatkan persalinan yang "mudah" dengan rasa sakit minimal. ${ }^{13}$ Permintaan ibu untuk kelahiran sesar seharusnya tidak dimotivasi oleh tidak tersedianya penanganan nyeri yang efektif. ${ }^{12}$ Ketidakmampuan ibu dalam mengatasi rasa sakit sejatinya dapat dijawab melalui anastesi epidural pada persalinan pervaginam. Akan tetapi, tidak jarang pasien kurang dapat memahami adanya kemudahan tersebut akibat stigma masyarakat terkait persalinan pervaginam yang sudah mengakar. ${ }^{13}$

Sejatinya, risiko komplikasi tidak hanya terdapat pada ibu. Pada bayi yang dilahirkan, risiko terjadinya gangguan pernapasan meningkat pada kelahiran dengan usia kehamilan kurang dari 39 minggu. ${ }^{10}$ Oleh karena itu, persalinan sesar atas permintaan ibu tidak boleh dilakukan sebelum usia kehamilan mencapai 39 minggu atau tanpa tindakan pematangan paru-paru bayi sebelum tindakan sesar dilakukan. ${ }^{9}$

The American College of Obstetricians and Gynecologists (ACOG) menyatakan bahwa persalinan sesar terencana memiliki beberapa potensi manfaat di antaranya dapat membantu ibu mengatur rencana pasca persalinan dan perawatan anak dengan lebih matang serta mengurangi risiko inkontinensia urin postpartum dalam jangka pendek, meskipun tingkat inkontinensia dua tahun setelah persalinan tidak berbeda secara signifikan antara kelahiran pervaginam dan bedah sesar. Selain itu, operasi sesar terencana dapat mengurangi risiko morbiditas dan mortalitas terkait kehamilan postterm dan risiko kecil kelahiran mati pada term akhir meskipun hal tersebut juga dapat ditangani dengan metode induksi. Persalinan sesar juga dinilai dapat mengurangi atau menghilangkan morbiditas dan mortalitas pada janin terkait proses persalinan pervaginam seperti: cedera pleksus brakialis yang berhubungan dengan distosia bahu; trauma pada tulang klavikula, tengkorak atau humerus, asfiksia yang berhubungan dengan kejadian intrapartum, seperti prolaps umbilikus atau abruptio placentae; penularan penyakit menular perinatal, termasuk HIV dan herpes simplek. ${ }^{14}$

\section{Tinjauan Etik}

Mengingat sederet rentetan risiko dan potensi manfaat yang ada, kemudian dalam pandangan etik, apakah boleh seorang dokter spesialis obstetri dan ginekologi melakukan tindakan sesar berdasarkan permintaan pasien tanpa adanya indikasi obstektrik yang nyata? Menyeimbangkan porsi beneficence, nonmaleficence, autonomi, dan justice dalam kasus ini menjadi kunci dalam menentukan sikap etik dokter.

Dalam suatu studi etik di Amerika, dilakukan peninjauan etik berdasarkan paradigma beneficence, autonomi, dan justice terhadap permintaan sesar tanpa indikasi medis. Secara beneficence, hingga saat ini keputusan klinis masih memandang persalinan pervaginam sebagai standar baku. Pada studi ini, terdapat opini bahwa tidak ada kewajiban berbasis otonomi untuk menawarkan kelahiran sesar dalam proses pemberian informasi yang etis dan legal. Adapun, dokter harus menanggapi permintaan pasien atas prosedur tersebut dengan informed consent yang menyeluruh dan meminta agar ibu mempertimbangkan kembali keputusannya untuk memastikan bahwa otonomi dilakukan dengan sungguh-sungguh. Menurut studi tersebut, dengan adanya informed consent menyeluruh, pemenuhan permintaan ibu secara etik diperbolehkan. ${ }^{15}$

Pada tahun 2006, The American College of Obstetricians and Gynecologists (ACOG) telah mengadakan pertemuan khusus membahas masalah ini. Pada pertemuan tersebut disepakati bahwa tindakan sesar atas permintaan pasien boleh dilakukan jika dokter telah memberikan informasi dalam bentuk informed consent yang jelas mengenai komplikasi akibat sesar yang dapat timbul seperti kematian ibu, emboli paru, infeksi, perlengketan, komplikasi anestesi, hingga kemungkinan operasi sesar ulangan pada kehamilan berikutnya. ${ }^{14}$ Pertanyaan berikutnya adalah, bagaimana kondisi di Indonesia?

Terbitnya UU tentang Praktik Kedokteran pada tahun 2004 yang menyatakan bahwa pasien memiliki tiga hak dalam pengobatannya kemudian dapat menjadi kerangka pertama dalam analisis kasus ini. Pertama, pasien berhak atas pilihan pengobatan pada dirinya. Pernyataan ini menguatkan bahwa permohonan persalinan sesar oleh pasien adalah hal yang dibenarkan. Kedua, pasien berhak untuk mendapatkan penjelasan atas tindakan medik yang akan dilakukan pada dirinya. Hal ini mengindikasikan kewajiban dokter untuk memberi penjelasan sejelas-jelasnya kepada pasien mengenai untung rugi tindakan dan risiko yang dihadapi selama pembedahan serta masa mendatang. Terakhir, pasien memiliki hak untuk 
menolak tindakan medis pada dirinya, dalam hal ini pasien dibenarkan untuk menolak rekomendasi persalinan pervaginam yang diberikan oleh dokter. ${ }^{16}$ Sementara dalam Kode Etik Kedokteran Indonesia (KODEKI) tahun 2012 pasal 10 ditegaskan bahwa dokter wajib menghormati hak-hak pasien. ${ }^{17}$

Dalam suatu studi dikatakan bahwa selain nilai autonomi dan beneficence terhadap ibu, beneficence terhadap janin juga perlu diperhatikan. Oleh karena itu, dokter berhak menolak permintaan pasien dengan pertimbangan tertentu yang disesuaikan dengan data pendukung yang ada. Meskipun demikian, terkait UU Praktik Kedokteran di mana Indonesia memercayai tiga hak pasien dengan dasar nilai autonomi pasien, studi tersebut menekankan untuk melakukan diskusi yang cukup dengan pasien untuk menghasilkan keputusan terbaik secara medis dan etik..$^{18}$ Sebelum dikeluarkannya suatu pedoman dalam kasus ini, sebuah informed consent yang dieksekusi secara eksplisit menjadi hal mendasar dalam membuat keputusan metode persalinan. ${ }^{19}$

Masalah ini juga telah dibahas secara intens oleh Persatuan Obestetri dan Ginekologi Indonesia (POGI) dalam pertemuan fetomaternal dan pertemuan tahunan POGI. Pada Pertemuan Ilmiah Tahunan (PIT) POGI di Jakarta, Juli 2011, telah disepakati untuk dilakukan perubahan pada standar kode etik POGI yang menyatakan bahwa tindakan seksio sesar atas permintaan pasien bukanlah merupakan suatu bentuk pelanggaran etik selama dilakukan suatu informed consent khusus, yaitu adanya surat persetujuan tindakan medik bedah sesar dengan format khusus yang isinya dijelaskan langsung oleh dokter yang akan melakukan tindakan, serta pengisiannya didampingi saksi dari pihak dokter dan saksi dari pihak pasien. Adapun surat persetujuan tindakan medik tersebut berisi: ${ }^{20}$

1. Permintaan yang tertulis secara eksplisit bahwa pasien meminta untuk dilakukan tindakan bedah sesar.

2. Pernyataan bahwa pasien telah mendapat penjelasan dari dokter yang akan melakukan pembedahan tentang:

a. persalinan secara sesar akan dilakukan walaupun berdasarkan pemeriksaan dokter, pasien dapat melahirkan pervaginam.

b. persalinan melalui sesar tidak lebih baik maupun lebih berisiko jika dibandingkan dengan persalinan pervaginam.

c. adanya risiko yang dapat timbul pada ibu dan janin berkaitan dengan tindakan bedah sesar.

Sebagai syarat lainnya, menurut rekomendasi ACOG, prosedur sesar dapat dilaksanakan dengan catatan usia kehamilan cukup bulan (mencapai 39 minggu). ${ }^{14}$ Selain itu, dokter harus dapat membantu memberi arahan yang jelas pada pasien mengenai informasi medis yang diperlukan terkait keputusan yang dimilikinyadalam rangka menghormati autonomi pasien dan memenuhi kewajiban dokter dalam optimasi kesehatan ibu dan janin. ${ }^{21}$

\section{KESIMPULAN}

Pada kondisi di mana tidak ada indikasi medis untuk dilakukan prosedur persalinan sesar, persalinan pervaginam menjadi pilihan persalinan yang paling aman dan wajib direkomendasikan oleh dokter. Akan tetapi mengingat hak pasien yang dinyatakan dalam UU Praktik Kedokteran tahun 2004, pasien dapat menolak dilakukan persalinan pervaginam dan mengajukan permohonan persalinan sesar. Permintaan persalinan sesar terencana oleh pasien yang tidak dilandasi oleh indikasi medis tersebut dapat dilaksanakan dengan syarat telah dilaksanakannya informed consent khusus, serta pada saat prosedur dilaksanakan usia gestasi tidak boleh kurang dari 39 minggu. Bila syarat tersebut dipenuhi, tindakan bedah sesar atas permintaan pasien dapat dibenarkan secara etik dan tidak melanggar kode etik POGI.

\section{KONFLIK KEPENTINGAN}

Tidak ada konflik kepentingan.

\section{REFERENSI}

1. Cunningham FG, Leveno KJ, Bloom SL, Spong CY, Dashe JS, Hoffman BL, et al. Williams Obstetrics. 24th ed. New York: McGraw-Hill Education; 2014.

2. Magowan B, Owen P, Thomson AJ. Clinical obstetrics and gynaecology. Philadelphia: Saunders; 2014. 435 p.

3. Gibbs RS, Karlan BY, Haney AF, Nygaard I, editors. Danforth's obstetrics \& gynecology. 10th ed. Philadelphia: Lippincott Williams \& Wilkins; 2012. $1152 \mathrm{p}$. 
4. The American College of Obstetricians and Gynecologists. Cesarean birth [Internet]. 2015 May [disitasi 2017 Jul 6]. Diunduh dari: https://www. acog.org/ $/$ media/For Patients/faq006.pdf

5. Menacker F, Declercq E, Macdorman MF. Cesarean delivery: Background, trends, and epidemiology. Semin Perinatol. 2006;30(5):235-41. doi: 10.1053/j.semperi.2006.07.002.

6. Coleman VH, Lawrence H, Schulkin J. Rising cesarean delivery rates: The impact of cesarean delivery on maternal request. Obstet Gynecol Surv. 2009;64(2):115-9. doi: 10.1097/ OGX.0b013e3181932dda.

7. Lee ASM, Kirkman M. Disciplinary discourses: Rates of cesarean section explained by medicine, midwifery, and feminism. Health Care Women Int. 2008;29(5):448-67. doi: 10.1080/07399330801949574.

8. Capitulo KL, Klein VR. Should pregnant women be able to choose elective cesarean as a birth option? MCN Am J Matern Nurs. 2010;35(5):252-3.

9. Latham SR, Norwitz ER. Ethics and "cesarean delivery on maternal demand." Semin Perinatol. 2009;33(6):405-9. doi: 10.1053/j. semperi.2009.07.009.

10. Norwitz ER. Cesarean delivery on maternal request [Internet]. 2017 [disitasi 2017 Jul 6]. Diunduh dari: http://www.uptodate.com/ contents/cesarean-delivery-on-maternal-request

11. Liu S, Liston RM, Joseph KS, Heaman M, Sauve R, Kramer MS. Maternal mortality and severe morbidity associated with low-risk planned cesarean delivery versus planned vaginal delivery at term. CMAJ. 2007;176(4):455-60. doi: 10.1503/ cmaj.060870.

12. NIH State-of-the-Science Conference Statement on cesarean delivery on maternal request. NIH Consens State Sci Statements. 2006;23(1):1-29.

13. Chestnut DH. Cesarean delivery on maternal request: Implications for anesthesia providers. Int J Obstet Anesth. 2006;15(4):269-72.
14. American College of Obstetricians and Gynecologists. Committee opinion no. 559: Cesarean delivery on maternal request. Obstet Gynecol. 2013;121(4):904-7. doi: 10.1097/01. AOG.0000428647.67925.d3.

15. Minkoff H, Powderly KR, Chervenak F, McCullough LB. Ethical dimensions of elective primary cesarean delivery. Obstet Gynecol. 2004;103(2):387-92. doi: 10.1097/01. AOG.0000107288.44622.2a.

16. Undang-Undang Republik Indonesia nomor 29 tahun 2004 tentang praktik kedokteran. 2004. Diunduh dari: http://www.idionline.org/wpcontent/uploads/2010/03/UU-No.-29-Th-2004-ttgPraktik-Kedokteran.pdf

17. Majelis Kehormatan Etik Kedokteran Indonesia. Kode etik kedokteran tahun 2012. Jakarta; 2012.

18. Minkoff $\mathrm{H}$. The ethics of cesarean section by choice. Semin Perinatol. 2006;30(5):309-12.

19. Lee YM, D'Alton ME. Cesarean delivery on maternal request: Maternal and neonatal complications. Curr Opin Obstet Gynecol. 2008;20(6):597-601. doi: 10.1097/ GCO.0b013e328317a293.

20. Perkumpulan Obstetri dan Ginekologi Indonesia. Panduan etika dan profesi obstetri dan ginekologi di Indonesia. Jakarta; 2012. Diunduh dari: http://pogi.or.id/publish/download/ dokumen-wajib-pogi/

21. Kalish RB, McCullough LB, Chervenak FA. Patient choice cesarean delivery: Ethical issues. Curr Opin Obstet Gynecol. 2008;20(2):116-9. doi: 10.1097/GCO.0b013e3282f55df7. 